\title{
Innovative strategies to improve the reach and engagement in pulmonary rehabilitation
}

\author{
Renae J. McNamara ${ }^{1,2,3}$, Marita Dale ${ }^{2}$, Zoe J. McKeough ${ }^{2}$ \\ ${ }^{1}$ Department of Physiotherapy, Prince of Wales Hospital, Sydney, Australia; ${ }^{2}$ Discipline of Physiotherapy, Faculty of Health Sciences, The University \\ of Sydney, Sydney, Australia; ${ }^{3}$ Woolcock Emphysema Centre, Woolcock Institute of Medical Research, The University of Sydney, Sydney, Australia \\ Contributions: (I) Conception and design: All authors; (II) Administrative support: None; (III) Provision of study materials or patients: None; (IV) \\ Collection and assembly of data: All authors; (V) Data analysis and interpretation: All authors; (VI) Manuscript writing: All authors; (VII) Final \\ approval of manuscript: All authors. \\ Correspondence to: Renae J. McNamara. Department of Physiotherapy, Prince of Wales Hospital, High Street, Randwick, NSW 2031, Australia. \\ Email: renae.mcnamara@health.nsw.gov.au.
}

\begin{abstract}
Evidence of personal and health-system benefits of pulmonary rehabilitation are undeniable. However, the capacity of traditional centre-based models to both reach and appeal to the intended population of people living with chronic obstructive pulmonary disease (COPD) remains difficult. It is well established that issues with access, suitability, referral, uptake, and attrition exist. Consequently, considerable energy has been invested into exploring innovative alternative modes of rehabilitation in an effort to increase the awareness and appeal, and expand the availability of pulmonary rehabilitation. The process of 'thinking differently' and 'pushing the boundaries' of clinical practice is underway, particularly in the United Kingdom and Australia, where new models of pulmonary rehabilitation are being evaluated. The number one priority is reaching the population of people with COPD and ensuring they are referred to rehabilitation services. Active case-finding in primary care, inviting health professionals and health consumers to pulmonary rehabilitation programs to increase understanding and awareness, and utilizing peer support via patient success stories, are just a few suggestions for increasing awareness of pulmonary rehabilitation. Once referred, engaging the population to complete a program is the next challenge. Marketing, patient co-design, alternative rehabilitation settings and modes of exercise training, use of technology, and focusing on modes which provide patient enjoyment and choice are all potential strategies to target in an effort to broaden the appeal and reduce the high attrition rate of traditional centre-based pulmonary rehabilitation programs. Reaching and engaging the target population in pulmonary rehabilitation is an important first step in people with COPD achieving successful outcomes from rehabilitation.
\end{abstract}

Keywords: Pulmonary rehabilitation; pulmonary disease; chronic obstructive; referral; technology

Submitted Aug 22, 2019. Accepted for publication Oct 15, 2019.

doi: $10.21037 /$ jtd.2019.10.29

View this article at: http://dx.doi.org/10.21037/jtd.2019.10.29

\section{Introduction}

Pulmonary rehabilitation features prominently in clinical guidelines worldwide (1-4), with strong recommendations for provision to all people with chronic obstructive pulmonary disease (COPD). Whilst historically pulmonary rehabilitation was developed and designed for people with COPD, the benefits of pulmonary rehabilitation in other chronic respiratory diseases such as interstitial lung disease and bronchiectasis (5-7) have also been demonstrated.

Despite the undisputed evidence for the positive benefits of pulmonary rehabilitation (8), the capacity of traditional centre-based models to reach the intended population remains difficult. Issues with access, suitability, referral, uptake, and attrition are well documented, and include cost of travel, lack of transport, inadequate knowledge of pulmonary rehabilitation, lack of perceived benefit, 
influence of referrer, and burden of comorbidities, among others (9-12). Consequently, researchers have set about identifying innovative ways to deliver evidence-based pulmonary rehabilitation to identify changes to clinical practice that ensure the chronic lung disease population receive the benefits of rehabilitation.

Healthy debate in the respiratory community is now emerging comparing traditional evidence-based pulmonary rehabilitation programs to alternative models. Questions are being asked about whether alternative models should be supported $(13,14)$. There remains concern about the implications of diminishing well-established traditional pulmonary rehabilitation services and the subsequent risk to acquired funding models given the strong evidence-base for pulmonary rehabilitation (8). These concerns need to be balanced against the desire to explore innovative strategies to develop person-preferred approaches to rehabilitation $(14,15)$. Previous editorials $(13,14)$ highlight important questions: what is the place for alternative interventions in pulmonary rehabilitation, and how do we ensure adequate rigor and robustness to accept alternative modes and models? The United Kingdom National Pulmonary Rehabilitation Audit Program (16) has been created to benchmark pulmonary rehabilitation in clinical practice, and is an important first step in understanding translation of programs in a real world setting and the impact they are having on people with chronic respiratory disease. However, the fact remains that the organisational aspects of pulmonary rehabilitation differ widely across the world (17), with various settings used such as inpatient, outpatient, community, and home-based (18), as well as the existence of high- and low-resourced programs often related to the wide variation in offerings between low to middle income countries and high income countries. Regardless of the debate surrounding pulmonary rehabilitation models, it is well acknowledged that we need to consider methods to increase the awareness and appeal, and expand the availability of pulmonary rehabilitation.

\section{Innovations in pulmonary rehabilitation}

The body of literature evaluating the effects of pulmonary rehabilitation is comprehensive, so much so that a Cochrane review advised additional randomised controlled trials are no longer warranted (19). However, the randomised controlled trials which have established the beneficial effects of pulmonary rehabilitation have primarily recruited the 'ideal' study population of people with COPD with few medical or physical barriers to attendance, who make up only a small proportion of the population who could benefit (20). In the world of clinical practice, the population is not as 'ideal' as those in clinical trials. What is evident is that we haven't succeeded in ensuring pulmonary rehabilitation is delivered to the entire population who need it (14), and the same services cannot continue to be offered with the expectation of the same results for a broader and diverse population. Therefore, there is a need to improve access by expanding the availability of pulmonary rehabilitation by exploring innovative models of pulmonary rehabilitation (21), and we need to improve the uptake of this worthy therapy. But what can we do differently? We need to reach and engage the desired population in new ways, and the United Kingdom and Australia are endeavouring to apply innovative strategies and research.

\section{Strategies to improve the 'reach' of pulmonary rebabilitation}

If our target population do not understand what pulmonary rehabilitation is, what participation involves, and how they can benefit from it $(22,23)$, why would they agree to attend? If referrers don't understand the program, how can they explain to the patient what to expect? It was in the late 1960s that Thomas L. Petty MD established what is thought to be the first outpatient pulmonary rehabilitation program (24), and it is interesting that 50 years later we still have an identity problem. Education is one of the key answers to these questions, and it is the role of all funders and providers of pulmonary rehabilitation to ensure the message of what pulmonary rehabilitation entails is known to referrers and people living with chronic respiratory disease.

We need to adopt a toolbox with a variety of approaches, and reach out to our target population in innovative ways. Firstly, with the majority of people with COPD living in the community and accessing healthcare through primary care, we need to better target this largely untapped market. An increase in the diagnosis of COPD has been demonstrated through active case finding in primary care $(25,26)$, and we need to ensure that when COPD management is subsequently developed for an individual, that referral to pulmonary rehabilitation occurs. The use of practice nurses and physiotherapists in primary care may assist in this detection and referral process $(27,28)$, and further research in this area is warranted. Secondly, open days, tours, 'taster' or 'try before you buy' sessions, and 
initiatives from pulmonary rehabilitation associations and patient foundations such as 'pulmonary rehabilitation week' $(29,30)$ improves exposure of pulmonary rehabilitation to the community thus increasing awareness. Research examining the effectiveness of community welcoming sessions, outreach, and early engagement initiatives deserves attention. Acceptability and feasibility will be important outcomes to address (31). Thirdly, the use of education videos and patient testimonial videos are being examined in the UK and Australia to assist with increasing referral and uptake of pulmonary rehabilitation $(32,33)$. These videos could be used for hospitalized patients or beyond the acute hospital setting and could be shown in outpatient and primary care clinics to provide information on the service such as program location, transport options, and availability of parking. Outcomes from this research will be interesting, and may show this to be a successful strategy for targeting people living with COPD. Finally, peer volunteers or lay health workers who are trained to support patients newly referred to pulmonary rehabilitation have been found to be well accepted by people with COPD, and this method of pairing new patients with lay health workers trained in behaviour change techniques is a method that could improve the uptake of pulmonary rehabilitation (34). Larger studies confirming the benefits of this avenue of support would be beneficial.

\section{Strategies to improve 'engagement' with pulmonary rebabilitation}

Misconceptions, misrepresentations or negative connotations surrounding pulmonary rehabilitation have been reported by people with chronic respiratory disease (23). Therefore, marketing pulmonary rehabilitation to people living with lung disease in a different way to capture their attention, provide appeal, and motivate them to want to attend may be a worthwhile strategy (35).

More recently, the role of patient co-design has been an important aspect in the development and redesign of healthcare delivery. Using the expertise and experiences of healthcare staff and patients in a genuine, equal and reciprocal relationship to develop a better healthcare experience for all is an approach that has been shown to result in better patient outcomes (36). In pulmonary rehabilitation, patient stakeholders have been central to identifying key benefits and challenges to attending rehabilitation in the United Kingdom (37). Interviews and focus groups researching the lived experience of participants who had attended pulmonary rehabilitation were conducted, and successful service re-design was achieved to improve communication and information, and improve transition points (service entry and discharge to a maintenance program), to increase engagement and program completion (37). Understanding the lived experiences of people with chronic respiratory disease and how they can be better educated about pulmonary rehabilitation will be pivotal to optimizing referral and delivery to programs. This innovative approach of patient co-design means insights can be translated into actionable strategies to maximise engagement, and ultimately completion of pulmonary rehabilitation.

In clinical practice, many programs around the world have adopted a variety of approaches to boost attendance rates, and patient engagement is important to improve retention. Opportunities for innovation in this area are endless and there is an appetite for change and further investigations. Our team has approached this challenge by investigating a variety of alternative settings and modes of exercise training, including investigating water-based exercise (38), tai chi (39), real-time video-conferencing telerehabilitation (40), ground-based walking (41), and community-based pulmonary rehabilitation (42) in an attempt to entice people with COPD to engage in a form of rehabilitation which most appeals to the individual. Further to this, research conducted in the United Kingdom and Australia (43-45) has indicated different models of homebased pulmonary rehabilitation are effective in providing a flexible and convenient pulmonary rehabilitation option that reduces the burden of travel (46) which is often reported as a barrier to attendance $(9,10)$. Additionally in the United Kingdom, alternative approaches using an online program of activity, coping and education self-management training (47), and a virtual model of pulmonary rehabilitation using videoconferencing to link a live pulmonary rehabilitation program to a rural site (48) have been investigated. The greatest appeal of these alternative programs is their success in reaching more people with COPD who may have been unable to attend and complete traditional centre-based pulmonary rehabilitation programs.

Are there further avenues to explore? Technology is rapidly advancing and could provide many options to expand the offering of pulmonary rehabilitation to better engage people with chronic respiratory disease in the future. Telerehabilitation is growing in popularity and is beneficial for people who don't reside near pulmonary rehabilitation centres (49). A recent Australian study of 254 people attending pulmonary rehabilitation found $78 \%$ of 
people regularly used a mobile phone, and $65 \%$ regularly used a computer or tablet (50). Sixty percent were also willing to use telerehabilitation (50). This demonstrates that a proportion of the pulmonary rehabilitation patient population have access to, and use technology in their daily lives, with the majority of those with access willing to utilize this technology for their healthcare. Whilst telerehabilitation has been most frequently examined, what about further use of technology beyond telerehabilitation? Active video games or 'exer-gaming' have been established as a beneficial tool for rehabilitation in other chronic diseases such as cancer, Parkinson's disease, and stroke (51). Research on the use of gaming technology in people with COPD is emerging, with studies reporting use of the Nintendo Wii Fit program and Microsoft Xbox Kinect as feasible and effective at improving exercise capacity and quality of life (52). Virtual reality technology and rehabilitation may be the way of the future with this technology currently being evaluated in the United Kingdom for ease of use and acceptability by people with COPD (53). Finally, the rapidly expanding world of e-health and mobile applications is being examined in the United Kingdom using the myPR application (54), and in Australia using the MH-COPD application (55). Both Australian and New Zealand researchers are developing mobile pulmonary rehabilitation applications which will feature text messaging support and enable patients to complete a pulmonary rehabilitation program directly from a smartphone $(56,57)$. The use of technology in pulmonary rehabilitation is exciting. However, future research needs to compare these innovative methods of delivering rehabilitation to the conventional model of pulmonary rehabilitation which has such strong evidence of effectiveness.

Should pulmonary rehabilitation programs focus more on enjoyment in order to engage patients through to program completion? Enjoyment translates to high adherence in the use of active video games such as the Nintendo Wii and Microsoft Xbox Kinect (52). In people with COPD engaged in water-based exercise training, enjoyment was rated highly as a factor enabling exercise program adherence and completion (58). The effect of exercise training modes which focus on personal hobby pursuits such as tai chi, yoga, Nordic walking, and dancing (15) may be the key to enticing and engaging with people not interested in participating in traditional gym-based exercise training. Future research is encouraged to establish the benefits of these alternative exercise training modes (15).

Whilst many new rehabilitation alternatives have been suggested and are being examined, how do we ensure pulmonary rehabilitation has the greatest appeal to patients? Ultimately this may come down to one simple concept - the idea of patient preference and providing choice from a variety of rehabilitation options to increase uptake and retention. In Australia, our clinical experience of offering different pulmonary rehabilitation options involves the provision of patient choice via a 'menu' of options. Following an initial assessment, and based on eligibility criteria and health and safety screening, patients are offered a choice of one of many supervised group exercise training modules-centre-based land (gym) exercise training, centre-based water (pool) exercise training, or home-based real-time video conferencing telerehabilitation; and patients are allocated to one or more individual or group education modules based on their medical screening history and lung disease knowledge (59). Modular education has been demonstrated to be an effective alternative to traditional education in cardiac rehabilitation (60), and work is currently underway evaluating this model in pulmonary rehabilitation (59).

The concept of a 'menu' of modular rehabilitation options could be taken one step further with the offering of a 'smorgasbord' of options where patients have the opportunity to 'taste test' many different rehabilitation options and transfer between different program settings and modes for variety (Figure 1). These proposed models of 'menu' and 'smorgasboard' options allow pulmonary rehabilitation to be truly individualised and personalized. Given that a barrier to uptake of pulmonary rehabilitation is inadequate patient knowledge (12), with potential poor health literacy in people with COPD (61), and with the additional challenges of patients lacking experience with pulmonary rehabilitation and the exercise equipment and technological aids utilized, what is the best way of presenting the possible pulmonary rehabilitation options to patients? Our experience is that the use of pictorial aids (photo boards) depicting the exercise and education settings, typical equipment used, and demonstrating the types of exercise and education and self-management delivery modes, are an important tool to present the different options to patients. Short videos and guided tours may be other methods utilized to pitch and tailor the presentation of options to individuals, and research in this area is warranted. 


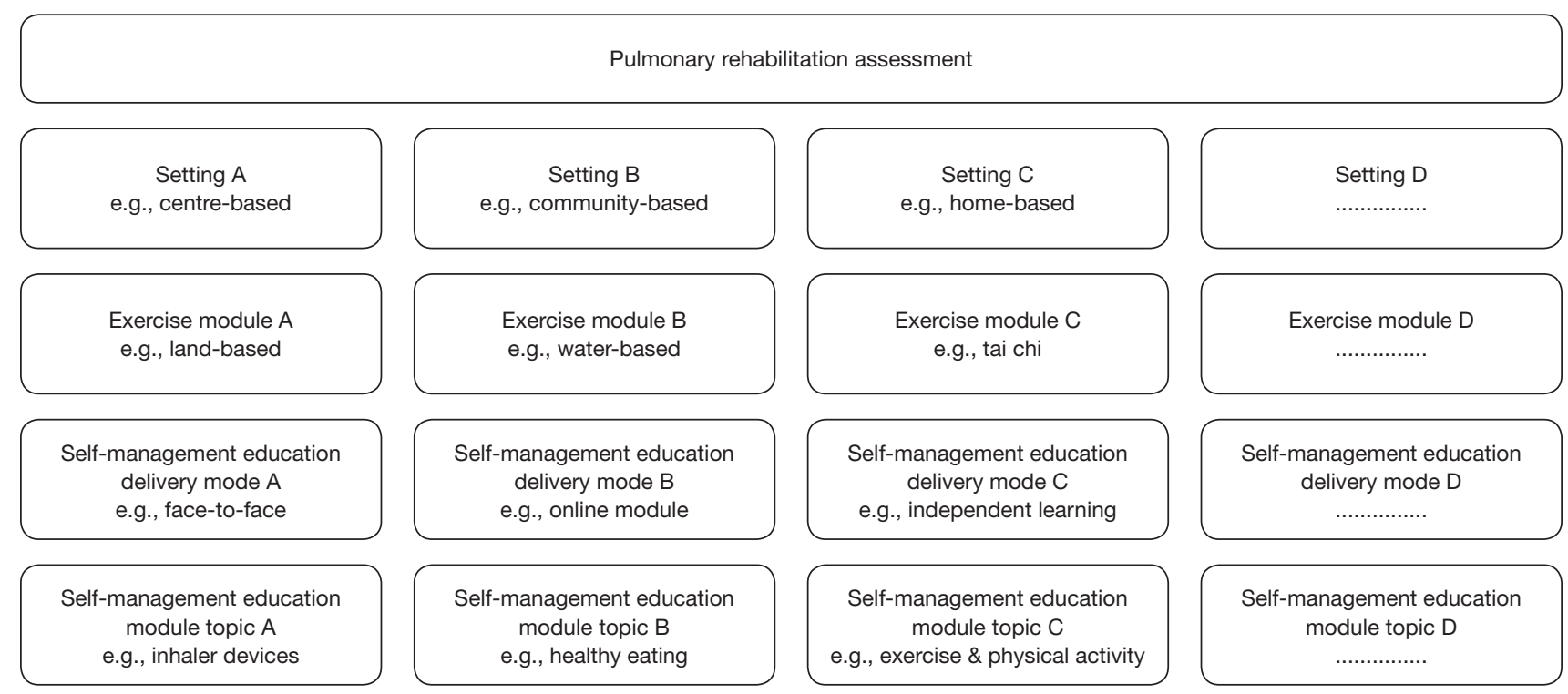

Figure 1 Schematic diagram of modular pulmonary rehabilitation. 'Menu' approach: a discreet selection of a setting type, an exercise module, a self-management education delivery mode, and personalized self-management education module topic/s. Example of a full 'menu' approach: setting B (community-based); exercise module C (tai chi); self-management education delivery mode A (face-to-face); self-management education module topics A, C, and D. 'Smorgasbord' approacb: multiple selections possible from setting type, exercise modules, self-management education module delivery modes, and self-management education module topics. Example of a 'smorgasbord' approach: setting A for 4 weeks (centre-based), then setting B for 4 weeks (community-based); exercise modules A (land-based) for 4 weeks, then exercise module B (water-based) for 4 weeks; self-management education delivery mode A (face-to-face) for self-management education module topic A (inhaler devices), then selfmanagement education delivery mode C (independent learning) for self-management education module topic B (healthy eating), etc.

\section{Beyond COPD}

Over the previous ten years there has been growing evidence for the benefit and safety of pulmonary rehabilitation in diseases such as interstitial lung disease $(5,7)$ and bronchiectasis (6), with Clinical Practice Guidelines acknowledging that people with these conditions, as well as others, should participate in pulmonary rehabilitation (62). Again, with this increasing evidence-base in diseases other than COPD, access to, and uptake of, pulmonary rehabilitation are being examined. Alternative methods of pulmonary rehabilitation delivery, including home-based pulmonary rehabilitation $(63,64)$ and telerehabilitation $(65)$, are being explored. The delivery of pulmonary rehabilitation in diseases other than COPD will continue to be an emerging field of research.

\section{Conclusions}

This review has discussed exciting and novel strategies for reaching and engaging people in pulmonary rehabilitation.
Suggestions for improving knowledge and understanding, referring, and improving the uptake and completion of pulmonary rehabilitation have been presented. As these strategies continue to be investigated, a greater body of knowledge will be developed to guide management decisions in the rehabilitation environment for chronic respiratory disease.

\section{Acknowledgments}

None.

\section{Footnote}

Conflicts of Interest: The authors have no conflicts of interest to declare.

Ethical Statement: The authors are accountable for all aspects of the work in ensuring that questions related to the accuracy or integrity of any part of the work are appropriately investigated and resolved. 


\section{References}

1. Qaseem A, Wilt TJ, Weinberger SE, et al. Diagnosis and Management of Stable Chronic Obstructive Pulmonary Disease: A Clinical Practice Guideline Update from the American College of Physicians, American College of Chest Physicians, American Thoracic Society, and European Respiratory Society. Ann Intern Med 2011;155:179-91.

2. National Institute for Health and Care Excellence (NICE). Chronic obstructive pulmonary disease in over 16s: diagnosis and management 2018. Available online: https:// www.nice.org.uk/guidance/ng115

3. Yang IA, Brown JL, George J, et al. The COPD-X plan: Australian and New Zealand guidelines for the management of chronic obstructive pulmonary disease 2018. Version 2.58, June 2019. Available online: https:// copdx.org.au/copd-x-plan/. Last accessed 12 August 2019.

4. Global Initiative for Chronic Obstructive Lung Disease (GOLD). Global strategy for the diagnosis, management, and prevention of chronic obstructive pulmonary disease 2019 report. Available online: https://goldcopd.org/wpcontent/uploads/2018/11/GOLD-2019-v1.7-FINAL14Nov2018-WMS.pdf. Last accessed 12 August 2019.

5. Dowman L, Hill CJ, Holland AE. Pulmonary rehabilitation for interstitial lung disease. Cochrane Database Syst Rev 2014;10:CD006322.

6. Lee AL, Hill CJ, McDonald CF, et al. Pulmonary rehabilitation in individuals with non-cystic fibrosis bronchiectasis: a systematic review. Arch Phys Med Rehabil 2017;98:774-782.e1.

7. Dowman LM, McDonald CF, Hill CJ, et al. The evidence of benefits of exercise training in interstitial lung disease: a randomised controlled trial. Thorax 2017;72:610-9.

8. McCarthy B, Casey D, Devane D, et al. Pulmonary rehabilitation for chronic obstructive pulmonary disease. Cochrane Database Syst Rev 2015;2:CD003793.

9. Keating A, Lee A, Holland AE. What prevents people with chronic obstructive pulmonary disease from attending pulmonary rehabilitation? A systematic review. Chron Respir Dis 2011;8:89-99.

10. Keating A, Lee AL, Holland AE. Lack of perceived benefit and inadequate transport influence uptake and completion of pulmonary rehabilitation in people with chronic obstructive pulmonary disease: a qualitative study. J Physiother 2011;57:183-90.

11. Hayton C, Clark A, Olive S, et al. Barriers to pulmonary rehabilitation: characteristics that predict patient attendance and adherence. Respir Med 2013;107:401-7.

12. Johnston KN, Young M, Grimmer KA, et al. Barriers to, and facilitators for, referral to pulmonary rehabilitation in COPD patients from the perspective of Australian general practitioners: a qualitative study. Prim Care Respir J 2013;22:319-24.

13. Casaburi R. Whither pulmonary rehabilitation? Will alternative modes help or hurt? Eur Respir J 2018;52:1801678.

14. Holland AE. Pulmonary rehabilitation for chronic obstructive pulmonary disease: has it peaked? Respirology 2019;24:103-4.

15. McNamara RJ, Spencer L, Dale M, et al. Alternative exercise and breathing interventions in chronic obstructive pulmonary disease: a critical review. EMJ Respir 2018;6:117-27.

16. Steiner M, McMillan V, Lowe D, et al. Pulmonary rehabilitation: An exercise in improvement. National Chronic Obstructive Pulmonary Disease (COPD) Audit Programme: Clinical and organisational audits of pulmonary rehabilitation services in England and Wales 2017. National report. London: RCP, 2018. Available online: https://www.rcplondon.ac.uk/projects/outputs/ pulmonary-rehabilitation-exercise-improvementcombined-clinical-and-organisational. Last accessed 12 August 2019.

17. Spruit MA, Pitta F, Garvey C, et al. Differences in content and organisational aspects of pulmonary rehabilitation programmes. Eur Respir J 2014;43:1326-37.

18. Spruit MA, Wouters EFM. Organizational aspects of pulmonary rehabilitation in chronic respiratory diseases. Respirology 2019;24:838-43.

19. Lacasse Y, Cates CJ, McCarthy B, et al. This Cochrane Review is closed: deciding what constitutes enough research and where next for pulmonary rehabilitation in COPD. Cochrane Database Syst Rev2015;11:ED000107.

20. Desveaux L, Janaudis-Ferreira T, Goldstein R, et al. An international comparison of pulmonary rehabilitation: a systematic review. COPD 2015;12:144-53.

21. Rochester CL, Vogiatzis I, Holland AE, et al. An official American Thoracic Society/European Respiratory Society policy statement: Enhancing implementation, use, and delivery of pulmonary rehabilitation. Am J Respir Crit Care Med 2015;192:1373-86.

22. Bott J, Dawson V. Pulmonary rehabilitation: clinical review and first-hand experience. Prac Nurs 2018;29:527.

23. Oxley R, Harrison SL, Rose A, et al. The meaning of the name of 'pulmonary rehabilitation' and its influence on 
engagement with individuals with chronic lung disease. Chron Respir Dis 2019;16:1479973119847659.

24. Casaburi R. A brief history of pulmonary rehabilitation. Respir Care 2008;53:1185-9.

25. Jordan RE, Adab P, Sitch A, et al. Targeted case finding for chronic obstructive pulmonary disease versus routine practice in primary care (Target COPD): a cluster-randomised controlled trial. Lancet Respir Med 2016;4:720-30.

26. Zwar NA, Bunker JM, Reddel HK, et al. Early intervention for chronic obstructive pulmonary disease by practice nurse and GP teams: a cluster randomized trial. Fam Pract 2016;33:663-70.

27. Bunker J, Hermiz O, Zwar N, et al. Feasibility and efficacy of COPD case finding by practice nurses. Aust Fam Physician 2009;38:826-30.

28. Dennis S. The effects of an innovative GPphysiotherapist partnership on health status for people with COPD (INTEGRATED): A pilot study. 2019. Trial registration: ACTRN12619001127190. Available online: https://www.anzctr.org.au/Trial/Registration/ TrialReview.aspx? $\mathrm{id}=377979 \&$ isReview $=$ true. Last accessed 14 August 2019.

29. American Association of Cardiovascular and Pulmonary Rehabilitation (AACVPR). Available online: https://www. aacvpr.org/Events-Education/Live-Workshops/CardiacPulmonary-Rehabilitation-Weeks. Last accessed 14 August 2019.

30. Pulmonary Education and Research Foundation (PERF). Available online: https://perf2ndwind.org/ pulmonary-rehabilitation-awareness-week/. Last accessed 14 August 2019.

31. Milner SC, Bourbeau J, Ahmed S, et al. Improving acceptance and uptake of pulmonary rehabilitation after acute exacerbation of COPD: Acceptability, feasibility, and safety of a PR "taster" session delivered before hospital discharge. Chron Respir Dis 2019;16:1479973119872517.

32. Barker RE, Jones SE, Banya $W$, et al. A video intervention to increase pulmonary rehabilitation uptake for patients hospitalized with acute exacerbations for COPD (virtue): A randomized controlled trial. Am J Respir Crit Care Med 2019;199:A5723.

33. Cox N, McDonald C, Jackson V, et al. Video testimonials may facilitate understanding of and referral to pulmonary rehabilitation in people with chronic respiratory disease. Thoracic Society of Australia and New Zealand Scientific Conference. Respirology 2019;24:22-102.

34. White P, Gilworth G, Lewin S, et al. Improving uptake and completion of pulmonary rehabilitation in COPD with lay health workers: feasibility of a clinical trial. Int J Chron Obstruct Pulmon Dis 2019;14:631-43.

35. West J. Does cardiac rehabilitation need a rebrand? British Heart Foundation 2018. Available online: https://www.bhf. org.uk/for-professionals/healthcare-professionals/articles/ update/does-cardiac-rehabilitation-need-a-rebrand. Last accessed on 21 July 2019.

36. Prestantia Health. Experience based co-design: a toolkit for Australia 2017. Available online: https://ahha.asn.au/ EBCDtoolkit/files/downloads/EBCD\%20toolkit\%20 Final.pdf. Last accessed on 25 July 2019.

37. Williams S, Turner A, Beadle H. Experience based co-design to improve a pulmonary rehabilitation programme. International Journal of Health Care Quality Assurance. Online first: http://dx.doi.org/10.1108/ IJHCQA-04-2018-0094.

38. McNamara RJ, McKeough ZJ, McKenzie DK, et al. Water-based exercise in COPD with physical comorbidities: a randomised controlled trial. Eur Respir J 2013;41:1284-91.

39. Leung RWM, McKeough ZJ, Peters MJ, et al. Short-form Sun-style t'ai chi as an exercise training modality in people with COPD. Eur Respir J 2013;41:1051-7.

40. Tsai LLY, McNamara RJ, Moddel C, et al. Home-based telerehabilitation via real-time videoconferencing improves endurance exercise capacity in patients with COPD: the randomized controlled TeleR study. Respirology 2017;22:699-707.

41. Wootton SL, Ng LWC, McKeough ZJ, et al. Groundbased walking training improves quality of life and exercise capacity in COPD. Eur Respir J 2014;44:885-94.

42. McNamara RJ, McKeough ZJ, Mo LR, et al. Communitybased exercise training for people with chronic respiratory and chronic cardiac disease: a mixed-methods evaluation. Int J Chron Obstruct Pulmon Dis 2016;11:2839-50.

43. Boxall AM, Barclay L, Sayers A, et al. Managing chronic obstructive pulmonary disease in the community. A randomized controlled trial of home-based pulmonary rehabilitation for elderly housebound patients. J Cardiopulm Rehabil 2005;25:378-85.

44. Holland AE, Mahal A, Hill CJ, et al. Home-based rehabilitation for COPD using minimal resources: a randomised, controlled equivalence trial. Thorax 2017;72:57-65.

45. Nolan CM, Kaliaraju D, Jones SE, et al. Home versus outpatient pulmonary rehabilitation in COPD: a propensity-matched cohort study. Thorax 2019;74:996-8. 
46. Lahham A, McDonald CF, Mahal A, et al. Home-based pulmonary rehabilitation for people with COPD: a qualitative study reporting the patient perspective. Chron Respir Dis 2018;15:123-30.

47. Mitchell KE, Johnson-Warrington V, Apps LD, et al. A self-management programme for COPD: a randomised controlled trial. Eur Respir J 2014;44:1538-47.

48. Knox L, Dunning M, Davies C, et al. Safety, feasibility, and effectiveness of virtual pulmonary rehabilitation in the real world. Int J Chron Obstruct Pulmon Dis 2019;14:775-80.

49. Holland AE, Cox NS. Telerehabilitation for COPD: could pulmonary rehabilitation deliver on its promise? Respirology 2017;22:626-7.

50. Seidman Z, McNamara R, Wootton S, et al. People attending pulmonary rehabilitation demonstrate a substantial engagement with technology and willingness to use telerehabilitation: a survey. J Physiother 2017;63:175-81.

51. Staiano AE, Flynn R. Therapeutic uses of active videogames: a systematic review. Games Health J 2014;3:351-65.

52. Simmich J, Deacon AJ, Russell TG. Active video games for rehabilitation in respiratory conditions: systematic review and meta-analysis. JMIR Serious Games 2019;7:e10116.

53. Manchester Metropolitan University. Researchers test if virtual reality app helps lung disease patients to exercise. 2017. Available online: https://www2.mmu.ac.uk/news-andevents/news/story/6821/. Last accessed: 27 May 2018.

54. Bourne S, DeVos R, North M, et al. Online versus faceto-face pulmonary rehabilitation for patients with chronic obstructive pulmonary disease: randomised controlled trial. BMJ Open 2017;7:e014580.

55. Ding H, Karunanithi M, Ireland D, et al. Evaluation of an innovative mobile health programme for the selfmanagement of chronic obstructive pulmonary disease (MH-COPD): protocol of a randomised controlled trial. BMJ Open 2019;9:e025381.

56. Whittaker R. A pilot study to assess the feasibility and acceptability of an adaptive mobile Pulmonary Rehabilitation (PR) programme to support people with chronic respiratory conditions. 2019. Trial registration: ACTRN12619000884101p. Available online: https:// www.anzctr.org.au/Trial/Registration/TrialReview. aspx?id=377590\&isReview=true. Last accessed 14 August 2019.

57. McKeough Z. Evaluation of the mobile pulmonary rehabilitation (m-PR) platform on exercise capacity and health status in people with chronic obstructive pulmonary disease (COPD): A randomised controlled trial. 2019. Trial registration: ACTRN12619001253190. Available online: https:// www.anzctr.org.au/Trial/Registration/TrialReview. aspx?ACTRN=12619001253190. Last accessed 10 October 2019.

58. McNamara RJ, McKeough ZJ, McKenzie DK et al. Acceptability of the aquatic environment for exercise training by people with chronic obstructive pulmonary disease with physical comorbidities: additional results from a randomised controlled trial. Physiotherapy 2015;101:187-92.

59. McNamara RJ, Tsai LLY, Alison JA. Improving pulmonary rehabilitation completion with exercise and education modules: the PuReMod trial [abstract]. Proceedings of the Australian Physiotherapy Association Conference, 2019.

60. Neubeck L, Freedman B, Lowres N, et al. Choice of Health Options in Prevention of Cardiovascular Events (CHOICE) replication study. Heart Lung Circ 2018;27:1406-14.

61. Omachi TA, Sarkar U, Yelin EH, et al. Lower health literacy is associated with poorer health status and outcomes in chronic obstructive pulmonary disease. J Gen Intern Med 2013;28:74-81.

62. Alison JA, McKeough ZJ, Johnston K, et al. Australian and New Zealand Pulmonary Rehabilitation Guidelines. Respirology 2017;22:800-19.

63. José A, Holland A, Oliveira C, et al. Does home-based pulmonary rehabilitation improve functional capacity, peripheral muscle strength and quality of life in patients with bronchiectasis compared to standard care? Braz J Phys Ther 2017;21:473-80.

64. Wallaert B, Duthoit L, Drumez E, et al. Long-term evaluation of home-based pulmonary rehabilitation in patients with fibrotic idiopathic interstitial pneumonias. ERJ Open Res 2019. doi: 10.1183/23120541.00045-2019.

65. Cox NS, McDonald CF, Alison JA, et al. Telerehabilitation versus traditional centre-based pulmonary rehabilitation for people with chronic respiratory disease: protocol for a randomised controlled trial. BMC Pulm Med 2018;18:71.

Cite this article as: McNamara RJ, Dale M, McKeough ZJ. Innovative strategies to improve the reach and engagement in pulmonary rehabilitation. J Thorac Dis 2019;11(Suppl 17):S2192S2199. doi: 10.21037/jtd.2019.10.29 